\title{
SMARTPHONE E INSTAGRAM: ALIADOS DO ENSINO DA TABELA PERIÓDICA
}

\author{
SMARTPHONE AND INSTAGRAM: ALLIES OF THE PERIODIC TABLE TEACHING
}

SMARTPHONE E INSTAGRAM: ALIADOS EN LA ENSEÑANZA DE LA TABLA PERIÓDICA

\author{
Carlos Alberto Vasconcelos \\ Pós doutor em Educação Contemporânea, Programa de Pós Graduação em Ensino de Ciências e \\ Matemática da Universidade Federal de Sergipe. E-mail: geopedagogia@yahoo.com.br. Orcid: \\ https://orcid.org/0000-0001-9049-5294 \\ Poliana Pereira da Silva \\ Mestre em ensino de ciências e matemática, pela Universidade Federal de Sergipe. E-mail: \\ polipds@gmail.com. Orcid: https://orcid.org/0000-0002-4874-4194
}

\section{RESUMO}

O presente texto traz um recorte de uma dissertação que teve como objetivo geral compreender como a Cultura da Convergência (JENKINS, 2009), por meio de uma sequência didática (SD), pode contribuir para a inserção das Tecnologias da Informação e Comunicação (TIC) no ensino da tabela periódica. Com o auxílio do smartphone e das redes sociais, a pesquisa — com abordagem qualitativa e descritiva (MINAYO, 2001; PRODANOV \& FREITAS, 2013) e do tipo investigação sobre a prática (PONTE, 2002) - foi desenvolvida com alunos do $9^{\circ}$ ano do Ensino Fundamental de uma instituição pública de ensino, ao longo de sete encontros. Neste recorte, apresentamos as atividades desenvolvidas no $4^{\circ}$ e $5^{\circ}$ encontro com os alunos: o Concurso de Imagens, via Instagram, para confecção de uma tabela periódica gigante. A partir dos registros escritos pelos estudantes, das observações feitas pela professora/investigadora e dos materiais coletados através das redes sociais, no intuito de verificarmos as contribuições da SD, dois aspectos foram analisados : o papel assumido pela professora/investigadora e como a aprendizagem significativa se processou - por meio da recepção e/ou da descoberta (AUSUBEL, 1963, 2003). Diante dos resultados obtidos, verificamos que a Cultura da Convergência - em especial, a cultura participativa - aplicada ao ensino da tabela periódica contribui para que o professor assuma o papel de facilitador, supervisor e mediador no processo de ensino-aprendizagem; ademais, espera-se que o educador promova situações onde a aprendizagem significativa aconteça por meio da descoberta, ao procurar apoio em subsunçores solidificados nas estruturas cognitivas dos alunos.

Palavras-chave: Tecnologias da informação e comunicação. Cultura da convergência. Smartphone. Redes sociais. Ensino da tabela periódica.

\section{ABSTRACT}

This text presents an excerpt from a dissertation whose general objective was to understand how Convergence Culture (JENKINS, 2009), through a didactic sequence (SD), can contribute to the insertion of Information and Communication Technologies (ICT) in teaching the periodic table. With the help of smartphones and social networks, the research - with a qualitative and descriptive approach (MINAYO, 2001; PRODANOV \& FREITAS, 2013) and the type of research on practice (PONTE, 2002) - was developed with 9 th grade elementary school students of a public educational institution over seven meetings. In this section, we present the activities developed in the 4th and 5th meeting with the students: the Image 
Contest, through Instagram, for the preparation of a Giant Periodic Table. From the records written by the students, the observations made by the teacher/researcher and the materials collected through social networks in order to verify the contributions of SD, we analyzed two aspects: the role assumed by the teacher/researcher and how meaningful learning was processed - through reception and/or discovery (AUSUBEL, 1963, 2003). In view of the results obtained, we verified that Convergence Culture - in particular, the participatory culture - applied to the teaching of the Periodic Table contributes to encourage the teacher to assume the role of facilitator, supervisor and mediator in the teaching-learning process; furthermore, it is expected that the educator promotes situations where meaningful learning takes place through discovery, seeking support in solidified subunits in students' cognitive structures.

Keywords: Information and communication technologies. Convergence culture. Smartphone. Social networks. Periodic table teaching.

\section{RESUMEN}

Este texto presenta un extracto de una disertación cuyo objetivo general era comprender cómo la Cultura de Convergencia (JENKINS, 2009), a través de una secuencia didáctica (SD), puede contribuir con la inserción de Tecnologías de Información y Comunicación (TIC) en la enseñanza de la tabla periódica. Con la ayuda de teléfonos inteligentes y redes sociales, la investigación - de enfoque cualitativo y descriptivo (MINAYO, 2001; PRODANOV \& FREITAS, 2013) y caracterizada como investigación sobre la práctica (PONTE, 2002) - , se desarrolló con estudiantes de noveno grado de la educación básica en una institución educativa pública durante siete reuniones. En esta sección, presentamos las actividades desarrolladas en la 4ta y 5 ta reunión con los estudiantes: concurso de imágenes, vía Instagram, para la preparación de una tabla periódica gigante. A partir de los registros escritos por los estudiantes, las observaciones realizadas por el profesor/investigador y los materiales recopilados a través de las redes sociales para verificar las contribuciones de la SD, dos aspectos fueron analizados: el papel asumido por el profesor/investigador y cómo se llevó a cabo el proceso de aprendizaje significativo - por medio de la recepción y/o descubrimiento (AUSUBEL, 1963, 2003). En vista de los resultados obtenidos, verificamos que la Cultura de Convergencia - en particular la cultura participativa - aplicada a la enseñanza de la tabla periódica contribuye para que el maestro asuma el papel de facilitador, supervisor y mediador en el proceso de enseñanza-aprendizaje; además, se espera que el educador promueva situaciones donde el aprendizaje significativo se produzca a través del descubrimiento, al recurrir a los subsunsores solidificados en las estructuras cognitivas de los estudiantes.

Palabras-clave: Tecnologías de la Información y la comunicación. Cultura de convergencia. Teléfono inteligente. Redes sociales. Enseñanza de la tabla periódica.

\section{INTRODUÇÃO}

É fato que a cada dia a comunicação via mobile se torna mais comum. Wi-fi ligado, internet conectada, notificações das redes sociais ativadas, lembretes e alarmes programados e aparelho sempre ao lado, quem não se identifica com essa descrição? É assim que muitos de nós atualmente nos relacionamos com os nossos smartphones. Crianças, jovens, adultos e idosos, independe da faixa etária ou do ambiente: é inegável a presença e a utilidade desses dispositivos no trabalho, na escola, na Igreja, nos momentos de lazer e em tantas outras atividades cotidianas.

Atualmente, estamos diante de um cenário de praticidade e familiaridade dos adultos com as Tecnologias da Informação e Comunicação (TIC). Nesse sentido, o que 
podemos dizer, então, das crianças e dos adolescentes que nunca viveram em um "mundo sem internet"? Tamanha é a intimidade que demonstram com os instrumentos tecnológicos e surpreendente é a habilidade com a qual manuseiam tais recursos. Se para os adultos e idosos a tela do smartphone, as conexões e funcionalidades de que dispõem são tão atraentes, o fascínio é ainda maior para as crianças e os adolescentes que vivem espontaneamente uma fase de descobertas.

Inclusive, referindo-se ao modo como nos relacionamos com as TIC, Prensky (2001) reconhece os nossos alunos como Nativos Digitais - tendo em vista que são "falantes nativos" da linguagem digital —, e nós, os que não nascemos em mundo digital, mas admiramos e adotamos muitos aspectos das tecnologias, os Imigrantes Digitais.

É curioso o fato como nós, professores, enquanto Imigrantes, embora tenhamos relativa destreza no uso do celular em nossas atividades cotidianas, muitas vezes encontramos dificuldades em falar a "língua nativa" dos alunos e resistimos à incorporação das TIC em nossa prática pedagógica. Utilizamos os smartphones diariamente para nos comunicarmos, nos informarmos, resolvermos questões pessoais e profissionais, no entanto, quando entramos na sala de aula, muitas vezes deixamos o celular de lado, nos voltamos para o quadro e começamos a ministrar a melhor aula expositiva que podemos para os nossos alunos.

Vale destacar que acreditamos que a aula expositiva em si não representa nenhum mal ou prejuízo ao processo ensino-aprendizagem. Muito pelo contrário, quando bem planejada, é capaz de produzir resultados pertinentes no processo de construção do conhecimento do aluno. Todavia, caso a aula expositiva seja a principal, ou até mesmo a única, estratégia de ensino utilizada em uma sala de aula com cerca de trinta alunos, por exemplo, de treze, quatorze anos de idade, cheios de energia, curiosidade e anseios para compreender o mundo e as pessoas que os cercam, com o "mundo na palma das suas mãos" através do smartphone; como esperar que eles, os alunos, fiquem atentos às "verdades emanadas" pelos professores ao longo de quatro, cinco horas por dia, cinco dias por semana — sem levar em consideração aqueles que estudam em tempo integral?

É inegável que o aluno de hoje, Nativo Digital, tem uma participação mais ativa no processo ensino-aprendizagem. Ele pensa, age e aprende de uma forma diferente dos Imigrantes Digitais. Se nós, professores, quisermos enfrentar essa realidade, precisamos rever nossa metodologia e nosso conteúdo (PRENSKY, 2001). 
Nesse cenário contemporâneo, ministrar aulas que despertem ainda mais o interesse e atraiam a atenção dos alunos tem sido um desafio diário para o professor. "Competir" com o conteúdo disseminado através do YouTube, das redes sociais e da internet, de forma geral, é, no mínimo, um trabalho custoso. O computador e, sobretudo, os smartphones, tornam essa batalha ainda mais difícil.

Diante dessa realidade, podemos - e devemos - nos questionar: por que nós, professores, ficamos tão desconfortáveis com o uso do celular no ambiente pedagógico? Por que não utilizar o smartphone em sala de aula? Ao invés de o enxergarmos como um inimigo, por que não tornar o aparelho em um aliado no processo ensino-aprendizagem?

É tempo de repensarmos a nossa prática pedagógica no intuito de atendermos a demanda atual da educação de incorporar as TIC dentro - e fora - - da sala de aula. Desse modo, o cotidiano escolar se tornará mais interessante e atraente tanto para os alunos quanto para os professores.

Acreditamos que a implementação intencional e planejada de conteúdos e estratégias de ensino mediadas adequadamente pelas TIC é fundamental para o caminhar desse árduo, mas também prazeroso, processo. No entanto, vale destacar que essa não é uma tarefa tão fácil.

Desta feita, e levando em consideração a popularização da internet e dos smartphones, o fácil e constante acesso às redes sociais, a mudança do paradigma da comunicação, dentre tantas outras demandas da sociedade informacional - centrada nas TIC (CASTELLS, 1999) - entendemos que precisamos ponderar o cenário e os desafios da escola do século XXI.

Diante de tais reflexões, decidimos abraçar o desafio de incorporar as TIC, de forma intencional e planejada no ensino da Tabela Periódica. Nesse sentido, buscamos apoio na Cultura da Convergência (JENKINS, 2009), visto que considera o potencial do smartphone no processo de construção e disseminação do conhecimento. Acreditamos que, quando bem definidos e planejados, os elementos da Cultura da Convergência podem contribuir para a inserção das TIC nas aulas de Química e, de forma mais específica, no processo ensino-aprendizagem da Tabela Periódica.

Padronizada internacionalmente pela União Internacional de Química Pura e Aplicada (IUPAC), encontramos na Tabela Periódica, de maneira organizada e sistematizada, os 118 elementos químicos atualmente conhecidos e suas respectivas 
propriedades físicas e químicas. Presente em todos os laboratórios, escolares e de pesquisas, nos livros didáticos e em diversas apostilas de Química, a Tabela é um instrumento rico em informação e conhecimento científico. De acordo com a Organização das Nações Unidas, 2019, o ano de aplicação da nossa investigação, foi definido como o Ano Internacional da Tabela Periódica. Tal escolha foi feita em homenagem aos 150 anos da Tabela.

Sendo assim, na tentativa de ampliarmos o material para o ensino da Tabela Periódica, construímos, desenvolvemos e investigamos atividades, por meio de uma sequência didática (SD), tendo como fundamento a Cultura da Convergência. Nesse sentido, o presente texto traz um recorte de uma dissertação que teve como objetivo geral o compromisso de compreender como a Cultura da Convergência, por meio de uma SD, pode contribuir para a inserção das TIC no ensino da Tabela Periódica. Com o auxílio do smartphone e das redes sociais, a pesquisa foi desenvolvida, ao longo de sete encontros, com os alunos do $9^{\circ}$ ano do Ensino Fundamental (EF) de uma instituição pública de ensino.

Neste recorte, apresentamos apenas as atividades desenvolvidas no quarto e quinto encontro com os alunos - e seus respectivos resultados: Concurso de Imagens, via Instagram, para confecção de uma Tabela Periódica Gigante. No intuito de verificarmos as contribuições da SD aplicada - e fundamentada na Cultura da Convergência - procuramos analisar dois aspectos: o papel assumido pela professora/investigadora, como também a forma como se deu o processamento da aprendizagem significativa - por meio da recepção e/ou da descoberta (AUSUBEL, 1963, 2003).

Concordamos com Leite (2018, p. 583) quando afirma que as tecnologias digitais “não são apenas um recurso para o ensino, são também eixos estruturantes de uma aprendizagem criativa, crítica, personalizada e compartilhada" e, por esse motivo, acreditamos no potencial da nossa investigação. Entendemos que a questão da convergência, não é só uma questão tecnológica, é sobretudo, cultural: as mudanças não devem ser apenas nos recursos didáticos utilizados em sala de aula, mas também, nas estratégias de ensino adotadas pelos professores.

\section{Metodologia}


Diante do exposto e em virtude da sua natureza, a presente investigação, de abordagem qualitativa (MINAYO, 2001) e descritiva (PRODANOV \& FREITAS, 2013), sendo do tipo investigação sobre a prática (PONTE, 2002). A investigação ocorreu em quatro etapas: 1) Formulação do Problema; 2) Recolha de Elementos, 3) Interpretação dos Dados e 4) Divulgação dos Resultados.

Os sujeitos da pesquisa foram os 26 alunos do $9^{\circ}$ ano do $\mathrm{EF}$, do turno vespertino, da escola da rede pública estadual de ensino a qual a investigadora faz parte do quadro efetivo de professores ${ }^{1}$. Os testes de sondagem, os questionários, os diversos registros escritos pelos alunos, as observações feitas pela professora/investigadora e os materiais coletados através das redes sociais foram fundamentais para o tratamento e análise dos dados.

Fizemos uso de uma adaptação da análise de conteúdo - proposta por Bardin (1977) - criando quatro categorias de análise que, certamente, foram relevantes para responder satisfatoriamente a questão central da pesquisa: como a Cultura da Convergência pode contribuir para a inserção das TIC no ensino da Tabela Periódica?.

Vale destacar que a preferência pela abordagem - qualitativa e descritiva - e pelo método citado anteriormente foi fruto da nossa necessidade de conseguir ajuda para compreender e lidar com o uso do smartphone e das redes sociais nas aulas de Ciências/Química do $9^{\circ}$ ano do EF - tendo em vista ser esse o primeiro contato oficial dos alunos com o estudo da Tabela Periódica. Entendemos que esse desafio precisava ser enfrentado de maneira intencional e planejada. Sendo assim, pesquisar a própria prática se tornou uma decisão oportuna.

A fim de buscar respostas a esse anseio, formulamos o nosso problema "como incorporar o uso do smartphone e das redes sociais no estudo da Tabela Periódica de maneira intencional, planejada e fundamentada?" - problema este, que apresenta íntima relação com a questão central da investigação - e, em seguida, partimos para o momento de recolha de elementos, ou seja, o momento da coleta dos dados.

Essa etapa pressupõe a elaboração de um plano de investigação. Sobre isso, Ponte (2002, p. 18) afirma que

\footnotetext{
${ }_{1}$ Por se tratar de uma pesquisa envolvendo seres humanos, e em respeito aos preceitos éticos estabelecidos na Resolução $n^{\circ} 466$ de 12 de dezembro de 2012 do Conselho Nacional de Saúde, a presente pesquisa foi registrada na Plataforma Brasil e aprovada, com parecer consubstanciado, pelo Comitê de Ética responsável.
} 
De um modo geral, as investigações sobre a prática recorrem aos planos de trabalho e às técnicas mais usuais das ciências sociais e humanas e, em particular, dos estudos em educação. No entanto, a investigação sobre a prática tem certas características salientes. Uma delas, que constitui o traço definidor, é o seu forte vínculo com os problemas da prática profissional.

Nesse sentido, visualizamos a necessidade de estruturar um plano de investigação que estivesse intimamente ligado ao plano de aula, visto que é o parceiro diário do professor na sua prática profissional.

Desse modo, como parte relevante do processo investigativo, elaboramos, desenvolvemos e analisamos uma SD baseada nas ideias de Delizoicov, Angotti e Pernambuco (2009). Por meio da utilização das TIC, a SD propunha uma série de atividades relacionadas aos principais elementos da Cultura de Convergência (JENKINS, 2009): convergência midiática, cultura participativa e inteligência coletiva.

A SD, intitulada Construindo uma Tabela Periódica Gigante, contava com uma série de Atividades Convergentes ${ }^{2}$ desenvolvidas ao longo de todo o processo investigativo. $\mathrm{O}$ Componente Curricular, a Unidade Temática, o Objeto de Conhecimento, a Especificação dos Objetos de Conhecimento e a Habilidade descrita nessa sequência foram extraídos do Currículo do Estado (2018, p. 506 e 507), fruto das contribuições de diversos profissionais da educação do Estado, lócus da investigação, e organizado a partir dos requisitos estabelecidos pela BNCC (2017) - ver Quadro 1.

Quadro 1 - Informações Gerais da Sequência Didática.

SEQUÊNCIA DIDÁTICA: CONSTRUINDO UMA TABELA PERIÓDICA GIGANTE

\begin{tabular}{|l|l|}
\hline 1. Componente Curricular: & Ciências da Natureza. \\
\hline 2. Unidade Temática: & Matéria e energia. \\
\hline 3. Objeto de Conhecimento: & Estrutura da matéria. \\
\hline $\begin{array}{l}\text { 4. Especificação dos Objetos } \\
\text { de Conhecimento: }\end{array}$ & $\begin{array}{l}\text { Orientar a construção de modelos da tabela periódica, utilizando de } \\
\text { preferência, diferentes materiais reaproveitados. }\end{array}$ \\
\hline 5. Habilidade: & $\begin{array}{l}\text { Conhecer os principais elementos e estrutura da tabela periódica, } \\
\text { relacionando a disposição dos elementos ao longo dos grupos, as } \\
\text { propriedades que apresentam, assim como investigar os componentes } \\
\text { químicos presentes em diferentes substâncias do cotidiano. }\end{array}$ \\
\hline 6. Público-alvo: & Alunos do 9 ${ }^{\circ}$ ano do EF. \\
\hline 7. Duração: & Sete aulas de 50 minutos cada. \\
\hline
\end{tabular}

2 Denominamos as atividades da SD como "Atividades Convergentes" pois buscamos incorporar conceitos da Cultura de Convergência - convergência midiática, cultura participativa e inteligência coletiva — em cada uma delas. 


\begin{tabular}{|c|c|}
\hline 8. Objetivo: & $\begin{array}{l}\text { Desenvolver a capacidade de abstração e a autonomia de ação e } \\
\text { pensamento, valorizando as relações dos alunos consigo mesmos, com } \\
\text { os outros, com a natureza, com as tecnologias e com o ambiente. }\end{array}$ \\
\hline 9. Recursos Materiais: & $\begin{array}{l}\text { Data show e computador; smart TV ou TV convencional com entrada } \\
\text { USB; smartphones (dos alunos e do professor); } 118 \text { folhas de papel A4; } \\
118 \text { placas de papelão ( } 20 \mathrm{~cm} \text { x } 20 \mathrm{~cm} \text { ); pistola e tubos de cola quente; } \\
\text { fita dupla face; régua; lápis; tesouras e um tubo grande de cola branca. }\end{array}$ \\
\hline 10. Referências: & 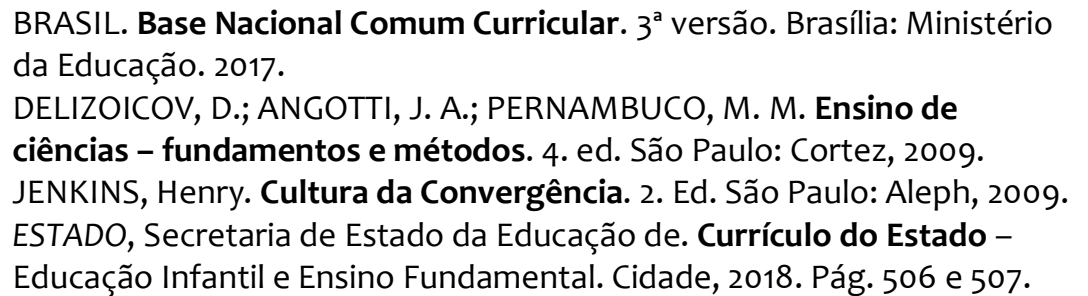 \\
\hline
\end{tabular}

Fonte: Elaboração própria (2019).

De acordo com Delizoicov, Angotti e Pernambuco (2009), a SD deve apresentar três momentos pedagógicos: a problematização inicial, a organização do conhecimento e a aplicação do conhecimento.

O momento da problematização inicial consiste em fazer um levamento dos conhecimentos dos alunos sobre o tema em questão - no nosso caso, sobre a Tabela Periódica. Em suma, esse é o momento mais adequado para expormos o problema, que pode ser uma temática, um conteúdo ou um conceito, e ouvir as concepções iniciais dos alunos acerca dele. É um momento de construção de hipóteses que pode ser iniciado por uma pergunta, um vídeo ou um texto e os alunos podem estar divididos em pequenos grupos ou não.

Após a problematização, vem o momento de Organização do Conhecimento. Aqui os alunos tem a oportunidade de buscar artifícios que os ajudem a responder os questionamentos estabelecidos na problematização. Através de pesquisas, livros, vídeos, experimentos, entrevistas com professores e/ou outras pessoas da comunidade (interna e/ou externa), os alunos irão buscar explicações que confirmem, ou não, as suas hipóteses.

Por fim, temos o terceiro, e último, momento pedagógico, que consiste na elaboração e produção dos alunos. O momento de Aplicação do Conhecimento, como é chamado, pode ser feito através de um cartaz, um vídeo, um texto, um resumo, uma exposição na comunidade escolar, dentre outras formas. É durante esse momento que os alunos colocam o conhecimento adquirido em prática e, então, retornam à problematização para reponder ao questionamento inicial. 
Conforme anunciamos anteriormente, no presente artigo nos deteremos apenas às atividades desenvolvidas ao longo do $4^{\circ}$ e $5^{\circ}$ encontro realizado com os alunos. Tais encontros consistem de parte do processo de construção coletiva de uma Tabela Periódica Gigante, e portanto, correspondem ao momento de Aplicação do Conhecimento - - de acordo com os momentos pedagógicos descritos anteriormente.

Sendo assim, em nossa investigação, após a problematização inicial e o momento de organização do conhecimento, desafiamos/incentivamos os alunos a construir coletivamente uma tabela periódica gigante, que foi afixada no corredor da escola.

No $4^{\circ}$ encontro, os alunos receberam as devidas instruções e orientações quanto à primeira etapa do processo de construção da tabela: o Concurso de Imagens, via Instagram - - detalhamos o plano de aula desse encontro no Quadro 2.

Quadro 2 - Plano de Aula do $4^{\circ}$ encontro com os alunos.

\begin{tabular}{|l|l|}
\hline \multicolumn{2}{|c|}{ SEQUÊNCIA DIDÁTICA: CONSTRUINDO UMA TABELA PERIÓDICA GIGANTE } \\
\begin{tabular}{|l|l|}
\hline 1. Introdução: & $\begin{array}{l}\text { Encontro: } N^{\circ} 4 . \\
\text { Duração: } 1 \text { aula de } 50 \text { minutos. } \\
\text { Público-alvo: alunos do } 9^{\circ} \text { ano do Ensino Fundamental. }\end{array}$ \\
\hline 2. Objetivo: & $\begin{array}{l}\text { Investigar os componentes químicos presentes em diferentes } \\
\text { substâncias do cotidiano. }\end{array}$ \\
\hline 3. Conteúdo Programático: & $\begin{array}{l}\text { Noções gerais da Tabela Periódica: grupos/famílias, períodos e séries dos } \\
\text { lantanídeos e actinídeos. }\end{array}$ \\
\hline Na presente aula, os alunos darão início ao concurso de imagens, de \\
acordo com as seguintes instruções:
\end{tabular} \\
$\begin{array}{l}\text { 4) } \text { Metodologimeiramente os alunos serão divididos em grupos com cerca de } \\
\text { quatro ou cinco componentes, } \\
\text { b) cada grupo será responsável por escolher no mínimo cinco elementos } \\
\text { químicos, sem que haja repetição entre os grupos, } \\
\text { c) os alunos deverão pesquisar duas imagens, de duas substâncias } \\
\text { distintas, que representem o elemento químico em questão (essa } \\
\text { escolha será para cada elemento selecionado anteriormente) e, } \\
\text { d) de posse das imagens, os alunos disponibilizarão enquetes no } \\
\text { Instagram para que os seus seguidores o ajudem no processo de escolha } \\
\text { das imagens que melhor representem os elementos químicos em } \\
\text { questão. Por exemplo, para o cálcio, qual imagem o representa melhor: } \\
\text { um esqueleto (ossos) ou um copo de leite? As imagens vencedoras irão } \\
\text { compor a Tabela Periódica Gigante. }\end{array}$ \\
$\begin{array}{l}\text { Observação 1: É bem provável que o tempo da aula não seja suficiente } \\
\text { para que os alunos concluam as pesquisas dos elementos e a promoção } \\
\text { das enquetes. Portanto, os mesmos deverão finalizar a atividade em } \\
\text { casa para que na próxima aula tenham condições de avançar para a } \\
\text { próxima etapa da construção da Tabela. }\end{array}$ \\
\hline
\end{tabular}




\begin{tabular}{|l|l|}
\hline & $\begin{array}{l}\text { Observação 2: Devido ao curto espaço de tempo para o } \\
\text { desenvolvimento da SD, as imagens dos elementos químicos que não } \\
\text { foram selecionados pelos alunos poderão/deverão ser providenciadas } \\
\text { pelo professor/investigador e/ou pelos alunos que se disponibilizarem a } \\
\text { assim fazê-lo, sem que haja a necessidade de fazer enquetes no } \\
\text { Instagram. }\end{array}$ \\
\hline Tabela Periódica e smartphone dos alunos com acesso a internet. \\
\hline 5. Recursos: & $\begin{array}{l}\text { Os alunos serão avaliados através dos registros escritos nas filipetas de } \\
\text { papel, da participação e produção das enquetes no Instagram e das } \\
\text { observações da professora. }\end{array}$ \\
\hline \multirow{5}{*}{ 7. Referências: } & $\begin{array}{l}\text { BRASIL. Base Nacional Comum Curricular. } 3 \text { a versão. Brasília: Ministério } \\
\text { da Educação. 2017. } \\
\text { DELIZOICOV, D.; ANGOTTI, J. A.; PERNAMBUCO, M. M. Ensino de } \\
\text { ciências - fundamentos e métodos. 4. ed. São Paulo: Cortez, 2009. } \\
\text { JENKINS, Henry. Cultura da Convergência. 2. Ed. São Paulo: Aleph, } 2009 . \\
\text { ESTADO, Secretaria de Estado da Educação de. Currículo do Estado - } \\
\text { Educação Infantil e Ensino Fundamental. Cidade, 2018. }\end{array}$ \\
\hline
\end{tabular}

Fonte: Elaboração própria (2019).

No $5^{\circ}$ encontro, os alunos compartilharam os resultados das enquetes realizadas por eles no Instagram, como também, iniciaram o processo de edição das imagens - e padronizaram a disposição das seguintes informações: nome, símbolo e número atômico dos elementos químicos através do smartphone - e o processo de recorte e colagem das imagens, já prontas, nas tiras de papelão. O Quadro 3 descreve detalhadamente o plano de aula deste encontro.

Quadro 3 - Plano de Aula do $5^{\circ}$ encontro com os alunos.

SEQUÊNCIA DIDÁTICA: CONSTRUINDO UMA TABELA PERIÓDICA GIGANTE

\begin{tabular}{|l|l|}
\hline 1. Introdução: & $\begin{array}{l}\text { Encontro: } \mathrm{N}^{\circ} 5 . \\
\text { Duração: } 1 \text { aula de } 50 \text { minutos. } \\
\text { Público-alvo: alunos do } 9^{\circ} \text { ano do Ensino Fundamental. }\end{array}$ \\
\hline 2. Objetivo: & $\begin{array}{l}\text { Investigar os componentes químicos presentes em diferentes substâncias } \\
\text { do cotidiano. }\end{array}$ \\
\hline 3. Conteúdo Programático: & $\begin{array}{l}\text { Noções gerais da tabela periódica: grupos/famílias, períodos e séries dos } \\
\text { lantanídeos e actinídeos. }\end{array}$ \\
\hline 4. Metodologia: & $\begin{array}{l}\text { Para a execução da presente aula, é necessário que os alunos estejam de } \\
\text { posse do resultado de todas as enquetes feitas na aula anterior e tenham } \\
\text { em mãos a relação das substâncias que representarão cada elemento } \\
\text { químico na Tabela Periódica Gigante. }\end{array}$ \\
$\begin{array}{l}\text { Inicialmente os alunos responderão, em grupo e por escrito, as seguintes } \\
\text { questões: “Quais elementos químicos foram escolhidos? Quais critérios } \\
\text { foram utilizados para a escolha de cada elemento? Onde podemos } \\
\text { encontrar os elementos químicos escolhidos? Qual a imagem vencedora }\end{array}$ \\
\hline
\end{tabular}




\begin{tabular}{|c|c|}
\hline & $\begin{array}{l}\text { na enquete realizada no Instagram?" Depois de respondidos, os } \\
\text { questionamentos, serão iniciados os processos de edição, recorte e } \\
\text { colagem das imagens escolhidas. } \\
\text { Para o melhor andamento da aula e aproveitamento do tempo, é } \\
\text { importante que o professor leve algumas imagens, já editadas, impressas } \\
\text { para que possa utilizar como referência da padronização que será } \\
\text { adotada, tendo em vista a grande quantidade de elementos químicos } \\
\text { contidos na tabela. } \\
\text { Enquanto alguns alunos editam as demais imagens com seus } \\
\text { smartphones, outros podem dar início ao processo de recorte e colagem } \\
\text { das outras que já foram disponibilizadas previamente pelo professor. } \\
\text { As imagens que irão compor a Tabela Periódica Gigante, com as suas } \\
\text { respectivas informações (nome, símbolo do elemento e número atômico), } \\
\text { serão coladas, cada uma, em tiras de papelão } 20 \text { x } 20 \text { cm com fita dupla } \\
\text { face ou com cola quente. } \\
\text { É importante destacar que ao final desta aula, ainda haverá imagens que } \\
\text { deverão ser impressas, recortadas e coladas nas tiras de papelão. Por isso } \\
\text { recomendamos que esse processo seja realizado num momento } \\
\text { extraclasse para que na próxima aula os alunos tenham condições de } \\
\text { avançar para a próxima etapa de construção da Tabela. } \\
\text { Ressaltamos ainda que esses itens e procedimentos são sugestões e, } \\
\text { dessa forma, não devem limitar a criatividade dos alunos caso estes } \\
\text { queiram ampliar o processo de criação da Tabela Periódica. }\end{array}$ \\
\hline 5. Recursos: & $\begin{array}{l}118 \text { folhas de papel A4 para impressão das imagens; } 118 \text { placas de papelão } \\
(20 \mathrm{~cm} \text { x } 20 \mathrm{~cm} \text { ); fita dupla face; pistola e tubos de cola quente; um tubo } \\
\text { grande de cola branca; rolinhos para ajudar a espalhar a cola e tesouras. }\end{array}$ \\
\hline 6. Avaliação: & $\begin{array}{l}\text { Os alunos serão avaliados através dos resultados das enquetes, dos } \\
\text { registros escritos sobre o processo de escolha dos elementos químicos e } \\
\text { da participação e envolvimento no processo de edição, recorte e colagem } \\
\text { das imagens. }\end{array}$ \\
\hline 7. Referências: & 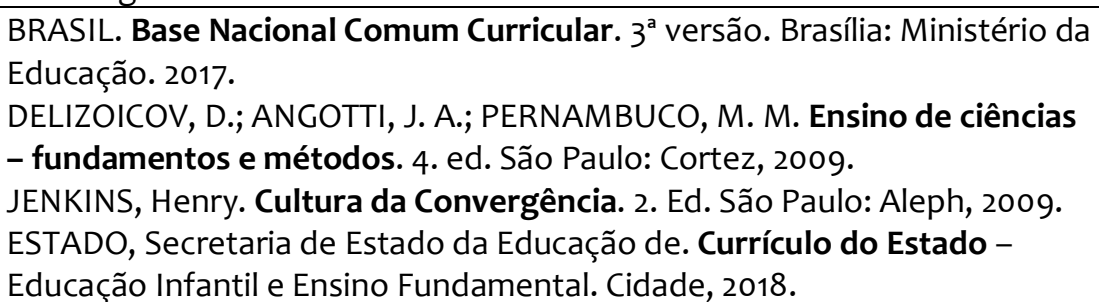 \\
\hline
\end{tabular}

Fonte: Elaboração própria (2019).

Dando sequência à investigação, após a etapa de recolha de elementos, por meio da SD, partimos para a análise e divulgação dos resultados. No entanto, reafirmando o que dissemos anteriormente, nos deteremos aqui, no presente texto, apenas a descrição e análise dos $4^{\circ}$ e $5^{\circ}$ encontros da SD.

\section{Resultados}


Neste recorte, nos propomos a analisar, de maneira específica, dois aspectos observados ao longo da execução dos $4^{\circ}$ e $5^{\circ}$ encontro da investigação: o papel assumido pela professora/investigadora, como também a forma como se deu o processamento da aprendizagem significativa - por meio da recepção e/ou da descoberta (AUSUBEL, 1963, 2003).

Em relação à postura adotada pela professora/investigadora - - primeiro aspecto analisado - corroboramos com as ideias de Leite (2018), no que diz respeito ao papel docente. Assim, acreditamos que

o professor atua como orientador, supervisor, facilitador do processo de aprendizagem, e não apenas como fonte única de informação e conhecimento. Para que possa ajudar o aluno, o facilitador pedagógico, primeiramente, deverá possuir um entendimento claro da construção de conhecimento enquanto processo dinâmico e relacional, advindo da reflexão conjunta sobre o mundo real. [...] Cabe ressaltar, que o aluno em contato com o instrumento (computador, smartphone, laptop etc.) e a informação, não é conduzido ao conhecimento, ele vai "copiar e colar". É preciso que o professor seja o mediador desse processo, ele deve ajudar o aluno a decidir sobre a direção de sua aprendizagem e a escolher entre múltiplas opções para aprender os conceitos requeridos (LEITE, 2018, p. 589-590, grifo nosso).

Nesse sentido, descrevemos e analisamos a seguir a postura adotada pela professora/investigadora ao longo do $4^{\circ}$ e $5^{\circ}$ encontro com os alunos, tendo como referência a descrição citada anteriormente.

Por se tratar de uma investigação sobre a prática, utilizamos como fonte de dados as observações da professora/investigadora, como também as ações e reações demonstradas pelos alunos ao longo das atividades.

No $4^{\circ}$ encontro, os alunos foram instruídos pela professora/investigadora sobre como seria realizado o concurso de imagens via Instagram. Divididos em cinco grupos, com até cinco participantes; cada grupo de alunos escolheu cinco elementos químicos, para que desse modo, através de pesquisas, identificassem substâncias onde tais elementos pudessem ser encontrados e porteriormente, publicar stories de enquetes no Instagram para que os seus seguidores pudessem participar da escolha das imagens que iriam compor a Tabela Gigante, o que caracterizou a cultura participativa proposta por Jenkins (2009).

Como um estudioso dos meios da comunicação e um grande fã dos reality shows americanos, Jenkins (2009, p. 378) entende por cultura participativa, aquela "cultura em 
que fãs e outros consumidores são convidados a participar ativamente da criação e da circulação de novos conteúdos" sobretudo, através do compartilhamento de informações através das redes sociais na internet.

Acerca da cultura participativa, Jenkins (2009) declara que a indústria do entretenimento busca, a partir das redes sociais, conhecer o perfil dos seus consumidores no intuito de elaborar um produto capaz de alcançar um público cada vez maior. Nesse processo, os consumidores acabam se tornando também produtores, visto que passam a participar do processo de construção e elaboração de novos conteúdos e novos produtos.

Ao longo de todo encontro, a professora/investigadora demonstrou uma postura de facilitadora e supervisora do processo, apenas indicando os meios/recursos para auxiliar os alunos na construção do conhecimento sobre a tabela periódica.

Notamos que essa postura esteve diretamente ligada à dos alunos: à medida que eles se mostravam mais envolvidos e engajados no desenvolvimento das atividades propostas, a professora assumia o papel de auxiliar no processo, não se responsabilizando pela produção deles, mas sim "ajudando o aluno a decidir sobre a direção de sua aprendizagem" (LEITE, 2018).

É interessante comentar que, nesse momento, foi curiosa a forma como a atenção dos alunos foi despertada ao verem uma imagem relacionada ao Instagram no material de apoio da professora/investigadora, no momento de explicação do concurso de imagens - especialmente algumas alunas que não costumavam ficar muito atentas às aulas e procuravam motivos para sair da sala e retornando apenas nos minutos finais.

Notamos que a partir daquela atividade, tais alunas começaram a se interessar pelas aulas de Ciências, como também, a participar ativamente das atividades propostas nos encontros vindouros. Uma delas se voluntariou para ajudar em atividades posteriores; enquanto a outra, passou a procurar a professora/investigadora na sala dos professores nos horários vagos de outras disciplinas, em busca de atividades extraclasse. Nesse sentido, notamos que a postura de mediação assumida pela professora provocou uma modificação positiva na relação aluna-professora.

A mesma postura de facilitadora e supervisora também foi observada no $5^{\circ}$ encontro com os alunos, tanto durante o preenchimento dos questionários, como no processo de edição, recorte e colagem das imagens. À professora/investigadora coube 
apenas a organização e providência dos meios necessários para a produção dos alunos, ou seja, a mesma atuou em todo o tempo como uma mediadora do processo de construção do conhecimento.

É importante destacar que não foi possível concluir o processo de edição, recorte e colagem no presente encontro. Desse modo, os alunos, voluntariamente, começaram a procurar a professora/investigadora em outros momentos e em outros ambientes da escola - sala dos professores, outras salas de aula - a fim de dar continuidade a produção/confecção das imagens em momentos extraclasse, demonstrando autonomia e não-dependência da professora para a execução das atividades.

Em suma, ao analisarmos o papel da professora/investigadora nos Encontros em destaque, concluímos que devido à natureza das atividades propostas, que exigiam a participação ativa dos alunos, à professora foi exigido que assumisse o papel de facilitadora, supervisora e mediadora.

Nesse sentido, percebemos que ao utilizar as TIC - smartphone e redes sociais - a professora/investigadora buscou aproximar-se da linguagem digital dos alunos, o que contribuiu para a construção de um ambiente favorável ao ensino da tabela periódica e, consequentemente, à aprendizagem dos alunos.

Aproveitando o ensejo, analisaremos a seguir o segundo aspecto citado anteriormente: a forma como a aprendizagem significativa se processou — por meio da recepção e/ou da descoberta (AUSUBEL, 1963, 2003). Utilizamos como fonte de dados, os registros escritos pelos alunos, as imagens obtidas nas redes sociais, como também as observações da professora/investigadora ao longo dos Encontros.

De acordo com Ausubel (1963), a aprendizagem corresponde à ampliação da estrutura cognitiva, à medida que novas ideias/informações vão sendo incorporadas a ela. A aprendizagem ocorre a partir da aquisição, armazenamento, organização e hierarquização de novas informações na estrutura cognitiva de um indivíduo.

Para que novos conhecimentos sejam formados, é necessário que as novas informações sejam ancoradas às estruturas cognitivas preexistentes e a depender de como essa incorporação acontece, a aprendizagem pode ser mecânica ou significativa.

Nesse sentido, aprendizagem significativa corresponde àquele processo onde uma nova informação vai se relacionar com um aspecto relevante da estrutura de conhecimento do indivíduo, chamado de subsunçor. Ainda, de acordo com o autor, o 
processamento da aprendizagem significativa pode se dar por meio da recepção ou por meio da descoberta.

\begin{abstract}
$\mathrm{Na}$ aprendizagem por recepção (por memorização ou significativa), o conteúdo total do que está por aprender apresenta-se ao aprendiz em forma acabada. A tarefa de aprendizagem não envolve qualquer descoberta independente por parte do mesmo. Ao aprendiz apenas se exige que interiorize o material (ex.: uma lista de sílabas sem sentido ou de pares de associações, um poema ou um teorema da geometria) que lhe é apresentado, de forma a ficar disponível e reproduzível numa data futura. Por outro lado, a característica essencial da aprendizagem pela descoberta (ex.: formação de conceitos, resolução de problemas por memorização ou significativa) é que o conteúdo principal do que está por aprender não é dado, mas deve ser descoberto de modo independente pelo aprendiz antes de este o poder interiorizar. Por outras palavras, a tarefa de aprendizagem distinta e inicial consiste em descobrir algo (AUSUBEL, 2003, p. 48).
\end{abstract}

De acordo com o autor, a aprendizagem por recepção é aquele processo onde tudo aquilo que é aprendido é apresentado ao aluno na sua forma final. Os conceitos já estão devidamente prontos e formulados. Isso pode acontecer através de um livro, uma aula, um filme, um jogo, uma palestra.

No entanto, vale destacar que a aprendizagem por recepção não está relacionada à passividade. O conteúdo de uma palestra, por exemplo, pode ser bastante mobilizador, a partir do momento que o indivíduo, diante dos conceitos apresentados, faz as devidas conexões cognitivas através dos seus subsunçores.

No processamento da aprendizagem por meio da descoberta, o conteúdo principal a ser aprendido deve ser descoberto pelo aluno. Ao invés de receber a informação pronta, ele precisa ir à busca dela, a fim de adquirir novos conceitos e ideias, fazendo as devidas conexões com os seus subsunçores; ou seja, o indivíduo deve se mobilizar e tentar construir um determinado conhecimento ou ideia.

Diante do exposto e analisando as enquetes realizadas pelos alunos no Instagram, no $4^{\circ}$ encontro, como também por meio das respostas às questões aplicadas no $5^{\circ}$ encontro, foi possível verificarmos como se deu o processamento da aprendizagem significativa.

Inicialmente, os alunos responderam algumas questões apresentando os elementos químicos e os critérios utilizados para a escolha de cada um deles, como 
também as substâncias onde podemos encontrá-los e quais as imagens vencedoras nas enquetes do Instagram - ver Figura 1.

Figura 1 - Captura de tela de algumas enquetes realizadas.

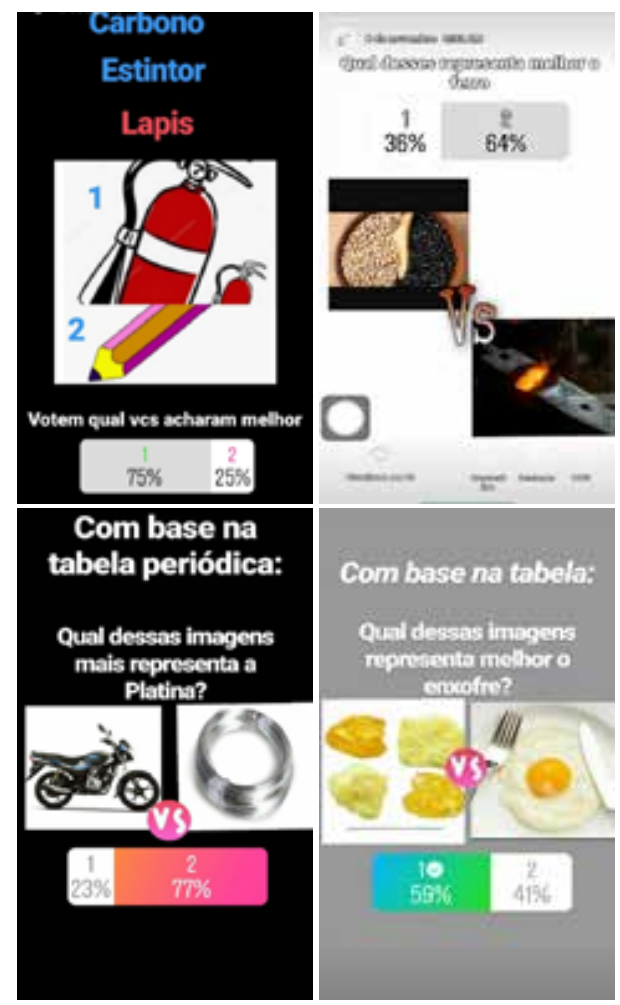

Fonte: Acervo da autora (2019).

Digitalizamos e destacamos aqui as respostas do Grupo 2 - ver Figura 2.

Figura 2 - Critérios de escolha dos elementos e imagens para as enquetes. 


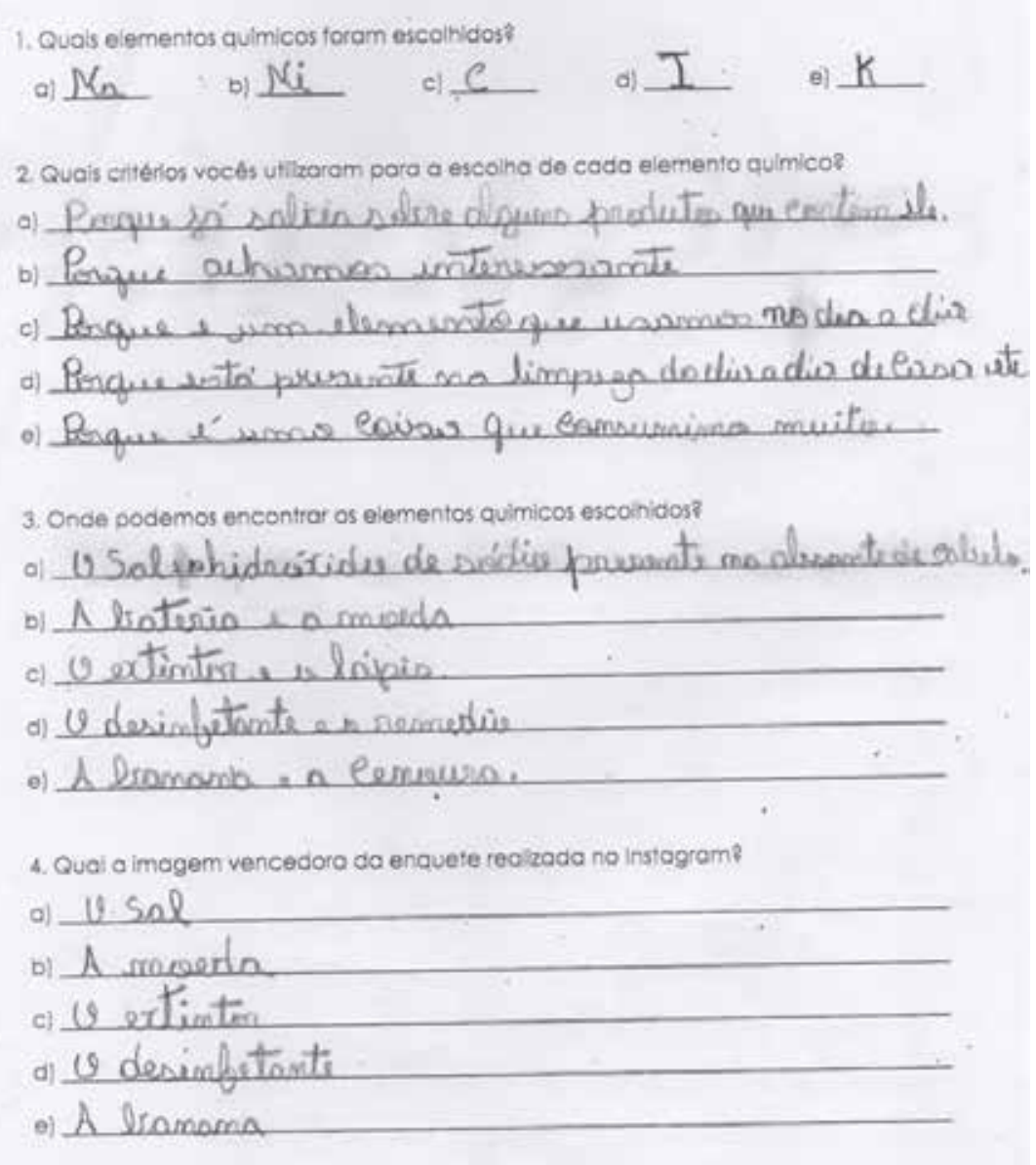

Fonte: Acervo da autora (2019).

Através das respostas apresentadas pelos alunos e das enquetes realizadas, observamos que o processamento da aprendizagem se deu por meio da descoberta: os alunos escolheram os elementos para que pudessem posteriormente pesquisar com seus smartphones e construir conhecimento referente a cada um deles.

Observamos também, a partir das respostas dos alunos, no item 2 do questionário, que os mesmos partiram de subsunçores solidificados em suas estruturas cognitivas, quando da escolha dos elementos de pesquisa.

Em suma, ao verificarmos como se deu o processamento da aprendizagem significativa nas atividades desenvolvidas nos respectivos encontros, percebemos que as Atividades Convergentes revelaram ser um material potencialmente significativo por processarem a aprendizagem por meio da descoberta - mobilizando assim, as estruturas cognitivas dos alunos para a ancoragem de novos conhecimentos significativos. 
Após o preenchimento dos questionários, os alunos deram início ao processo de edição, recorte e colagem das imagens. Enquanto uns editavam as imagens no celular, a fim de padronizar as informações dos elementos, outros recortavam e colavam as imagens que a professora investigadora levou, previamente, a fim de otimizar o tempo, tendo em vista a grande quantidade de elementos químicos na Tabela - ver Figura 3.

Figura 3 - Alunos confeccionando as imagens da Tabela Gigante.

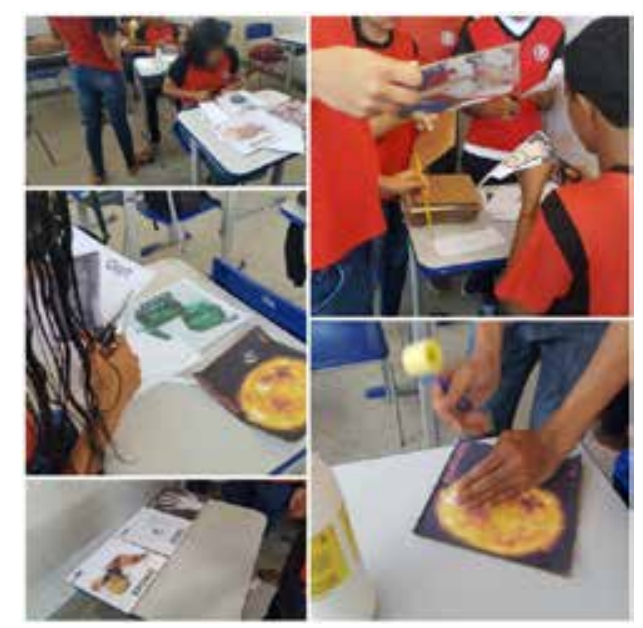

Fonte: Acervo da autora (2019).

Por fim, nos despedimos deste tópico com a imagem da Tabela Periódica Gigante que fora produzida pelos alunos e afixada no corredor da escola por eles mesmos — ver Figura 4.

Figura 4 - Tabela Periódica Gigante dos Elementos Químicos.

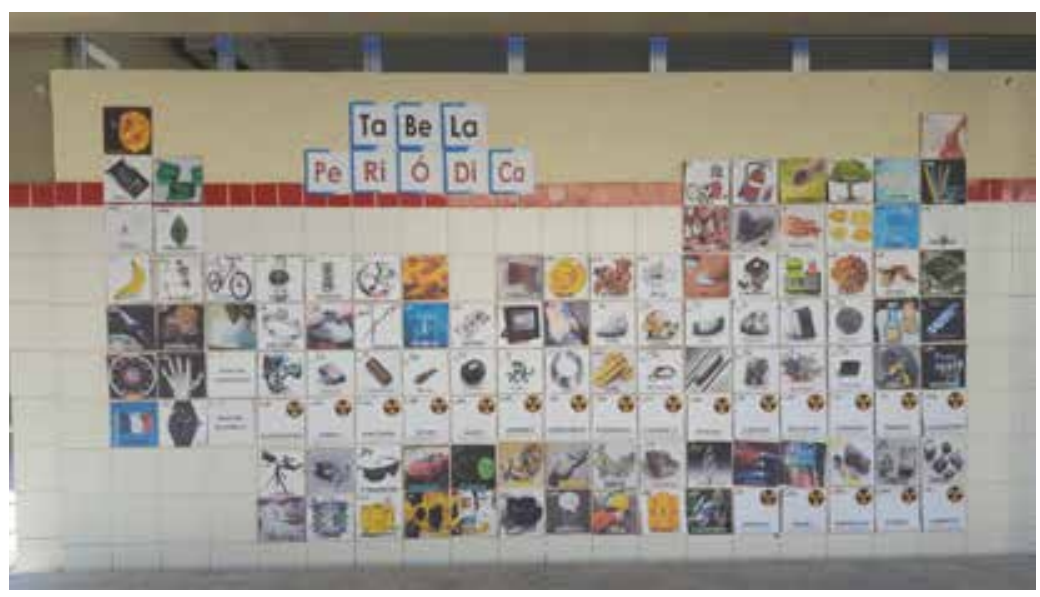

Fonte: Acervo da autora (2019). 


\section{CONSIDERAÇÕES FINAIS}

Diante do cenário informacional em que estamos inseridos, das mudanças que temos observado e dos novos desafios que a escola da sociedade contemporânea vem enfrentando, acreditamos que é necessária, para não dizer urgente, a elaboração de estratégias didáticas que contemplem a inserção das TIC no ensino de Química e, sobretudo no ensino da tabela periódica.

Nesse sentido, acreditamos que os elementos que caracterizam a Cultura da Convergência podem contribuir para a inserção das TIC e para a criação de um ambiente favorável tanto ao processo de ensino, como à aprendizagem significativa - no presente texto nos referimos particularmente à cultura participativa.

Acreditamos que a mudança que necessitamos é profunda e perpassa por uma questão cultural: não foram apenas as tecnologias que evoluíram, mas também a forma como nos relacionamos com elas . Nós, professores, Imigrantes Digitais, precisamos enfrentar o desafio de incorporar as TIC em nossas estratégias de ensino, de maneira intencional e planejada. Precisamos nos aproximar dos nossos alunos, falantes nativos da linguagem digital.

Sendo assim, assumimos aqui, nesta investigação, o compromisso de compreender como a Cultura da Convergência, por meio de uma SD, pode contribuir para a inserção das TIC no ensino da tabela periódica.

Diante dos resultados obtidos ao longo do $4^{\circ}$ e $5^{\circ}$ encontro do nosso plano de investigação - presentes neste recorte de dissertação - verificamos que a Cultura da Convergência aplicada ao ensino da tabela periódica contribui: impulsionando o professor a assumir o papel de facilitador, supervisor e mediador do processo ensino aprendizagem e promovendo situações onde a aprendizagem significativa se processa por meio da descoberta, ao procurar apoio em subsunçores solidificados nas estruturas cognitivas dos alunos.

No entanto, vale salientar que, através dessa pesquisa, não buscamos apontar um único, exclusivo e/ou melhor caminho para o ensino da tabela periódica. Compreendemos que cada contexto apresenta suas necessidades e potencialidades particulares. Nesse sentido, apresentamos aqui uma possibilidade que se mostrou efetiva e, que, 
certamente, tem capacidade para fomentar as discussões/reflexões sobre a inserção das TIC no ensino da tabela periódica, por meio da Cultura da Convergência.

Acreditamos que os frutos dessa investigação são de extrema relevância, visto que atendem a demanda atual da educação de formar cidadãos ativos na construção do conhecimento, através da incorporação das TIC, por meio da Cultura da Convergência, no ensino da tabela periódica.

\section{REFERÊNCIAS}

AUSUBEL, D. P. Aquisição e retenção de conhecimentos: uma perspectiva cognitiva. 1. ed. Lisboa: Paralelo Editora, 2003.

AUSUBEL, D. P. The psychology of meaningful verbal learning. New York: Grune and Stratton, 1963.

BARDIN, Laurence. Análise de conteúdo. Lisboa: Edições 70, 1977.

BRASIL. Base Nacional Comum Curricular. $3^{\text {a }}$ versão. Brasília: Ministério da Educação, 2017.

CASTELLS, M. A sociedade em rede: a era da informação, economia, sociedade e cultura. 6. ed. São Paulo: Paz e Terra, 1999.

DELIZOICOV, D.; ANGOTTI, J. A.; PERNAMBUCO, M. M. Ensino de ciências - fundamentos e métodos. 4. ed. São Paulo: Cortez, 2009.

ESTADO, Secretaria de Estado da Educação de. Currículo do Estado - educação Infantil e ensino fundamental. Cidade, 2018.

JENKINS, Henry. Cultura da convergência. 2. ed. São Paulo: Aleph, 2009.

LEITE, Bruno Silva. Aprendizagem tecnológica ativa. Revista internacional de educação superior. Campinas/São Paulo, v.4, n.3, set./ dez. 2018, p. 580-609.

MINAYO, Maria Cecília de Souza (org.). Pesquisa social: teoria, método e criatividade. Petrópolis: Vozes, 2001.

PONTE, João Pedro da. Investigar a nossa própria prática. In: GTI (org.), Reflectir e investigar sobre a prática profissional . Lisboa: APM, 2002.

PRENSKY, Marc. Digital natives, digital immigrants. On the horizon, NCB University Press, v. 9, n. 5, oct. 2001. 
PRODANOV, Cleber Cristiano; FREITAS, Ernani César de. Metodologia do trabalho científico: métodos e técnicas da pesquisa e do trabalho acadêmico. 2. ed. Novo Hamburgo: Feevale, 2013.

Recebido em: 16/02/2020

Parecer em: 30/03/2020 Aprovado em: 10/03/2021 